Proceedings

\title{
Enhanced Condensational Growth in the Upper Airways Induced by Specific Climatic Conditions as a Major Factor for Increased Deposition of Inhaled Aerosols: Short Report ${ }^{\dagger}$
}

\author{
Alexander N. Ishmatov ${ }^{1, *}$ \\ Research Institute of Experimental and Clinical Medicine, Novosibirsk 630117, Russian Federation \\ * Correspondence: ishmatoff@rambler.ru; ishmatoff@centercem.ru; Tel.: +7-913-249-7837 \\ + Presented at the 2nd International Electronic Conference on Environmental Health Sciences, 4-29 \\ November 2019, available online: https://sciforum.net/conference/IECEHS-2. \\ Published: 5 November 2019
}

\begin{abstract}
While significant advances have been made in understanding the aerosol dosimetry in the last decades, many aspects of adverse effects on respiratory health as weather conditions and environmental or occupational air contaminants require further development. It was found that weather patterns can play a significantly more important role in the deposition of ambient submicron aerosols in human airways than previously assumed and unusually high underestimation of deposition efficiency may be typical for most classical studies and approaches.
\end{abstract}

Keywords: air pollution; airways; respiratory health; hygroscopic growth

\section{Enhanced Condensational Growth (ECG) as A Pulmonary Drug Delivery Method}

It is well known that only a very limited deposition of aerosol particles in the submicron range $(100 \mathrm{~nm}-1000 \mathrm{~nm})$ occurs in the respiratory tract, due to a lack of sufficient inertia and Brownian motion for efficient deposition [1,2]. It is also commonly accepted that a small size increase due to the hygroscopic growth under normal conditions in human airways does not lead to a significant increase in the deposition of submicron aerosols [3-8].

In fact, the low pulmonary deposition of inhaled nano- and submicron particles is one of the primary limitations of the current generation of inhaled pharmaceuticals. The pharmaceutical delivery of nano- and submicron particles to the respiratory system offers a unique opportunity, because such particles possess a small size with a large surface area, together with altered dissolution properties compared to micrometer-sized particles. However, pulmonary deposition is low, with approximately $70 \%$ of the particles exhaled [9-12].

To solve this problem the enhanced condensational growth (ECG) method was proposed and used as a respiratory drug delivery platform $[13,14]$. This approach consists of creating short-term supersaturated conditions (when relative humidity (RH) of air inside airways exceeds $100 \%$ ) in the upper airways during inhalation. Under such conditions, the condensation of water vapor onto droplet surfaces causes the significant condensational growth of inhaled submicron particles up to 3-7 $\mu \mathrm{m}$, which should ensure full lung retention $[15,16]$.

To create the supersaturation in the airways the inhalation of warm saturated air a few degrees above body temperature were used in ECG platform: inhalation of warm-humid air of $\mathrm{T}=40^{\circ} \mathrm{C}, \mathrm{RH}$ $=100 \%$, and hot-humid air of $\mathrm{T}=47^{\circ} \mathrm{C}, \mathrm{RH}=100 \%[13,14,16]$. 


\section{Enhanced Condensational Growth (ECG) as A Problem in An Everyday Life}

It is obvious that supersaturated conditions in the airways may be induced by specific environmental conditions in our everyday life, potentially leading to enhanced deposition of ambient submicron aerosols and particulate matters in the respiratory tract. This effect would be similar to the deposition of submicron drug particles in the pulmonary drug delivery platform where ECG is used. $\mathrm{Xi}$ et al. [16] concluded that high deposition rates of inhaled aerosols in hot-humid environments, or on a hot and humid day, might indicate higher health risks to individuals than normal environmental conditions or on a regular day. Therefore, they summarized that people under such conditions would have a higher possibility of developing respiratory symptoms and connected such conditions with manufacturing workplaces (such as industries of paper, textile, mining, food, industries), humidified hospital units, and specific tropical geographical locations.

However, the most interesting and important point is the observation on the onset of supersaturation in the nasopharyngeal/oropharyngeal regions and upper airways during cool/cold air inhalation $\left(\mathrm{T}<10-20^{\circ} \mathrm{C}\right)$ which was indicated in the other studies [17-24]. Because such conditions like cold weather and cold seasons could be associated with the possibility of the onset of supersaturation in the human airways. Thus, there is a real risk of a higher possibility of developing respiratory symptoms associated with enhanced deposition of inhaled aerosols due to the effect of ECG in the airways for millions of people in the world.

\section{National Ambient Air Quality Standards of Inhaled Particles and ECG}

National ambient air quality standards of inhaled particles use well-known standard methods of estimation of inhaled doses of ambient aerosols. For reference, the International Commission on Radiological Protection (ICRP) deposition model [25] and Multiple-Path Particle Dosimetry Model (MPPD) [26] commonly used for this aims.

The problem of the classical view on the deposition of ambient aerosols in the airways exist in the postulate that under any external or environmental conditions, the conditions inside human airways will be 'normal' $\left(\mathrm{RH}=90-99.5 \%\right.$; $\left.\mathrm{T}=30-37^{\circ} \mathrm{C}\right)$ (see the related review in [27]). However, as was shown above the conditions in the airways can be supersaturated $(\mathrm{RH}>100 \%)$, and it can lead to effects of unlimited ECD and induce enhanced deposition of inhaled aerosols and particulate matter in the airways. Furthermore, Haddrell et al [28] concluded that: "the sensitivity to the ambient RH is typically not considered in lung inhalation models; in the literature review made during the preparation of this manuscript, no articles discussing this point were found." Such a state of affairs has not changed in recent years. Thus, nearly all computational fluid dynamics (CFD) studies do not consider the possibility of air oversaturation/supersaturation in the airways and the nearly all CFD studies do not consider even sensitivity to the change in ambient RH.

\section{ECG and Hygroscopic Growth in the Airways: What Is the Difference?}

There are many existing studies that use the hygroscopic growth model on computational lung aerosol dynamics, - and this is not a problem for the estimation of health risks connected with hygroscopic growth. Almost all known studies use such models to meet their aims: health risks assessments, pulmonary drug delivery, aerosol deposition, national ambient air quality standards, and etc. For reference, under normal conditions in the airways ( $\mathrm{RH}=90-99.5 \%$; $\mathrm{T}=30-37^{\circ} \mathrm{C}$ ), hygroscopic and condensational growth of inhaled particles are limited by a growth factor of 1.3-1.7 (with a maximum of 4 in rare cases) [3-8]. While the ECG under supersaturated conditions (RH > $100 \%$ ) in the airways which could be induced by cold weather can lead to practically unlimited growth of inhaled particles (growth factor of more than 10-20).

That's why the ECG effects allow to significantly increase the deposition of inhaled submicron aerosols of pharmaceuticals in the airways: an exhaled fraction of aerosol decreases from $70 \%$ to $0 \%$ $[13,14,16]$. It is obvious that the deposition rate of ambient aerosols and particulate matter in the 
submicron size range for which ECG is most pronounced can significantly increase as it happens with aerosols in pulmonary drug delivery platforms where ECG used.

\section{Conclusion}

Air pollution and deposition of ambient aerosols in human airways are associated with many detrimental health effects. National ambient air quality standards of inhaled particles are mainly based on the particulate concentration and sizes. While the impact of the climatic or weather conditions on the possibilities potentially leading to effects of ECG and enhanced deposition of ambient submicron aerosols in the respiratory tract is not taken into account.

Thus, a significant scientific gap can exist within the present knowledge on the estimation of deposition of ambient submicron aerosols in the human airways under different climatic conditions (especially for $\mathrm{T}<20{ }^{\circ} \mathrm{C}$ ). The presented work improves our picture on the effect of atmospheric conditions on the humidity driven growth and enhanced deposition of submicron aerosols inside the human airways.

Funding: This research was not funded by any organization or university and did not receive any specific grant from funding agencies in the public, commercial, or not-for-profit sectors.

Conflicts of Interest: The authors declare no conflict of interest.

\section{References}

1. Brown, R.C., Air Filtration: An Integrated Approach to the Theory and Applications of Fibrous Filters. Pergamon Press, Oxford. 1993, eBook ISBN: 9780080912608.

2. Maze, B.; Vahedi Tafreshi, H.; Wang, Q.; Pourdeyhimi, B., A simulation of unsteady-state filtration via nanofiber media at reduced operating pressures. J. Aerosol Sci. 2007, 38, 550-571. https://doi.org/10.1016/j.jaerosci.2007.03.008.

3. Martonen, T.B.; Bell, K.A.; Phalen, R.F.; Wilson, A.F.; Ho, A., Growth rate measurements and deposition modelling of hygroscopic aerosols in human tracheobronchial models. Ann Occup Hyg. 1982, 26, 93-108. https://doi.org/10.1093/annhyg/26.1.93.

4. Li, W.; Hopke, P.K., Initial size distributions and hygroscopicity of indoor combustion aerosol particles. Aerosol. Sci. Technol. 1993, 19, 305-316. https://doi.org/10.1080/02786829308959638.

5. Robinson, R.J.; Yu, C.P., Theoretical analysis of hygroscopic growth rate of mainstream and sidestream cigarette smoke particles in the human respiratory tract. Aerosol. Sci. Technol. 1998; 28(1):21-32. https://doi.org/10.1080/02786829808965509.

6. Vu, T.V.; Delgado-Saborit, J.M.; Harrison, R.M., A review of hygroscopic growth factors of submicron aerosols from different sources and its implication for calculation of lung deposition efficiency of ambient aerosols. Air. Qual. Atmos. Hlth. 2015, 8(5):429-440. https://doi.org/10.1007/s11869-015-0365-0.

7. Winkler-Heil, R.; Ferron. G.; Hofmann, W., Calculation of hygroscopic particle deposition in the human lung. Inhal. Toxicol. 2014, 26(3):193-206. https://doi.org/10.3109/08958378.2013.876468.

8. Vu, T.V.; Ondracek, J.; Zdimal, V.; Schwarz, J.; Delgado-Saborit, J.M.; Harrison, R.M., Physical properties and lung deposition of particles emitted from five major indoor sources. Air Qual. Atmos. Hlth. 2016, https://doi.org/10.1007/s11869-016-0424-1.

9. Card, J.W.; Zeldin, D.C.; Bonner, J.C; Nestmann, E.R., Pulmonary applications and toxicity of engineered nanoparticles. Am. J. Physiol. Lung Cell Mol. Physiol. 2008, 295(3):L400-11. https://doi.org/10.1152/ajplung.00041.2008.

10. Cohen, B.S.; Sussman, R.G.; Lippmann, M., Ultrafine Particle Deposition in a Human Tracheobronchial Cast. Aerosol. Sci. Technol. 1990, 12(4):1082-1091. https://doi.org/10.1080/02786829008959418.

11. Jaques, P.A.; Kim, C.S.,Measurement of total lung deposition of inhaled ultrafine particles in healthy men and women. Inhal. Toxicol. 2000, 12(8):715-31. https://doi.org/10.1080/08958370050085156.

12. Stahlhofen, W.; Rudolf, G.; James, A.C., Intercomparison of Experimental Regional Aerosol Deposition Data. J. Aerosol Med. 1989, 2(3):285-308. https://doi.org/10.1089/jam.1989.2.285.

13. Longest, P.W.; McLeskey, J.T.; Hindle, M., Characterization of Nanoaerosol Size Change During Enhanced Condensational Growth. Aerosol. Sci. Technol. 2010, 44(6):473-483. https://doi.org/10.1080/02786821003749525. 
14. Longest, P.W.; Tian, G.; Hindle. M., Improving the lung delivery of nasally administered aerosols during noninvasive ventilation-an application of enhanced condensational growth (ECG). J. Aerosol Med. Pulm. Drug Deliv. 2011, 24(2):103-18. https://doi.org/10.1089/jamp.2010.0849.

15. Longest, P.W.; Xi, J.; Hindle, M., Effective delivery of nanoparticles and micrometer-sized pharmaceutical aerosols to the lung through enhanced condensational growth. 2008, US Patent 8,479,728. US20110056492A1. https://patents.google.com/patent/US8479728.

16. Xi, J.; Xiuhua, A.Si.; Jong, W.K., Characterizing Respiratory Airflow and Aerosol Condensational Growth in Children and Adults Using an Imaging-CFD Approach. In Heat Transfer and Fluid Flow in Biological Processes. 2015, ISBN: 978-0-12-408077-5, Sid Becker and Andrey Kuznetsov ed. (Elsevier B.V), pp. 125-155. https://doi.org/10.1016/B978-0-12-408077-5.00005-5.

17. Ferron, G.A., The size of soluble aerosol particles as a function of the humidity of the air. Application to the human respiratory tract. J. Aerosol Sci. 1977, 8(4):251-267. https://doi.org/10.1016/0021-8502(77)90045-3.

18. Ferron, G.A., Deposition of hygroscopic aerosol particles in the lungs. In: Marijnissen J.C.M., Gradon L. (eds) Aerosol Inhalation: Recent Research Frontiers. Springer, Dordrecht 1996; https://doi.org/10.1007/978-94-009-1694-4_7.

19. Ferron, G.A.; Haider, B.; Kreyling, W.G., Conditions for measuring supersaturation in the human lung using aerosols. J. Aerosol Sci. 1984, 15(3):211-215. https://doi.org/10.1016/0021-8502(84)90065-X.

20. Ferron, G.A.; Haider, B.; Kreyling, W.G., A method for the approximation of the relative humidity in the upper human airways. Bull. Math. Biol. 1985, 47(4):565-89. https://doi.org/10.1016/S0092-8240(85)90022-9.

21. Ferron, G.A; Haider, B.; Kreyling, W.G., Inhalation of salt aerosol particles-I. Estimation of the temperature and relative humidity of the air in the human upper airways. J. Aerosol Sci. 1988, 19, 343-363. https://doi.org/10.1016/0021-8502(88)90274-1.

22. Sarangapani, R.; Wexler, A.S., Growth and neutralization of sulfate aerosols in human airways. J. Appl. Physiol 1996, 81(1):480-90. https://doi.org/10.1152/jappl.1996.81.1.480.

23. Grasmeijer, N.; Frijlink. H.W.; Hinrichs, W.L.J., An adaptable model for growth and/or shrinkage of droplets in the respiratory tract during inhalation of aqueous particles. J. Aerosol Sci .2016, 93:21-34. https://doi.org/10.1016/j.jaerosci.2015.11.011.

24. Ingelstedt, S., Studies on the conditioning of air in the respiratory tract. Acta Otolaryngol. Suppl. 1956, 131:1-80. PMID: 13381446.

25. ICRP Human respiratory tract model for radiological protection, a report of a task group of the International Commission on radiological protection. Ann ICRP. 1994;24(1-3):1-482. PMID: 7726471.

26. Multiple-path particle deposition (MPPD 2.1, beta version): A model for human and rat airway particle dosimetry by Applied Research Associates Raleigh. ARA. 2016. https://www.ara.com/node/561.

27. Elad, D.; Wolf, M.; Keck, T., Air-conditioning in the human nasal cavity. Respir. Physiol. Neurobiol. 2008, 163(1-3):121-7. https://doi.org/10.1016/j.resp.2008.05.002.

28. Haddrell, A.E.; Davies, J.F.; Reid, J.P., Dynamics of particle size on inhalation of environmental aerosol and impact on deposition fraction. Environ. Sci. Technol. 2015, 49(24):14512-14521. https://doi.org/10.1021/acs.est.5b01930.

(C) 2019 by the authors. Submitted for possible open access publication under the terms and conditions of the Creative Commons Attribution (CC BY) license (http://creativecommons.org/licenses/by/4.0/). 